\title{
Ihmisten ulkomuodon luonnehtiminen kansankielessä
}

\begin{abstract}
Muutamia vuosikymmeniä sitten jouduin Tammelan Hykkilässä usein kuuntelemaan vanhan setämiehen Jussilan Kallen kertomuksia ja kuvauksia. Hänen puhekielensä oli rytmillistä ja kuvausvoimaista, hänen sanontansa ja sananpartensa tuoreita ja sattuvia. Tuntui kuin hän olisi helposti voinut luoda uusia ilmaisuja. Kun hän oli kärkäs esittämään lähimmäisistään arvosteluja, jotka ilmeisesti perustuivat tarkkoihin havaintoihin, tulin niitä merkinneeksi muistiin ja julkaisin niistä lyhyen yhteenvedon. ${ }^{1}$

Tällainen kokeilu innosti minut 1943 julkaisemaan kehotuksen kilpakeräykseen aiheesta "Miten kansa arvostelee lähimmäisiään ruumiinmuotojen ja luonteenominaisuuksien puolesta".2 Tarkoituksena oli saada tutkimusaineistoa kansamme luonnekuvaan. Ohjekirjoituksessa kehotin vastaajia panemaan pääpainon ihmisten luonteenominaisuuksia kuvaaviin sanoihin ja sananparsiin, vaikkakin samalla olisi merkittävä muistiin vastaavaa aineistoa myös ihmisten ulkomuodosta ja olemuksesta, koska näytti siltä, että usein sama sanonta viittasi sekä ruumiinrakenteeseen että luonteeseen ja hengenlahjoihin. Keräyksessä saatettiin noudattaa sellaista menetelmää, että etsittiin rinnakkain vastakohtia, esim. ihmisten hyviä ja huonoja ominaisuuksia. Kun lisäksi pyydettiin merkitsemään muistiin, mitä kerääjät toisten kertomana tai omana arvostelunaan sanovat kuvaamistaan henkilöistä tai yleensä ihmisten eriläisista luonteen-
\end{abstract}

1 Esкo AaLtoneN Hämäläinen kansanmies arvostelee heimoaan. Julkaistu Suomen Kuvalehdessä 1938, 34 ja teoksessa Lounais-Hämeen entisyyttä (1953), s. 134 -

2 Kotiseutu 1943, vihko $1-2$, sivut $38-40$. 
ominaisuuksista, oli viitottu tie arvostuksien alueelle. Kehotin myös lähemmin kuvaamaan henkilöitä, jotka kotipaikallaan olivat herättäneet huomiota ulkonäöllään, luonteenominaisuuksillaan tai käyttäytymisellään.

Lähinnä kai sota-ajan vuoksi kilpakeräykseen osallistui vain 33 henkilöä. Saalis käsitti yht. 2272 sanalippua ja 135 arkkia. ${ }^{3}$ Vastaajista oli muita kaikkia huomattavasti edellä J. Leppänen, jonka aineisto oli Karstulan Kivijärveltä ja Kinnulasta.

Näinkin suppean keräyksen tulos on varsin antoisa ja sanavarastoltaan monipuolinen. Kun Sanakirjasäätiön laajoissa kokoelmissa on varmaan samaa ja samantapaista aineistoa monikymmenkertainen määrä, todistaa tämä runsaus, että entisajan primääriryhmissä tarkkailtiin, kuvailtiin ja arvosteltiin ihmisten ulkomuotoa ja luonteenlaatua erittäin halukkaasti. Yleisesti annettiin yksilöille kutsuma- eli liikanimiä fyysisten tai psyykkisten ominaisuuksien mukaan. Kun tällaisten liikanimien joukosta tapaa sanoja, jotka ovat säilyneet myös vanhoissa paikannimissä (kormu, karsto, rontti, haippo, upero), ovat nämä mahdollisesti saaneet alkunsa mainitunlaisen liikanimen kantajasta. Ihmisen ruumiinrakennetta tai luonnetta kuvastavat nimitykset liittyivät herkästi tiettyyn ihmiseen, josta ne saatettiin yleistää. Tätä osoittavat seuraavat nimenantoselitykset Karstulan alueelta.

Kinnulassa eli suurikokoinen, veltto-olentoinen suutari, jota ominaisuuksiensa vuoksi sanottiin lonkaiseksi. Samanlaisista henkilöistä käytetään täällä vieläkin (1943) lonkaisen nimitystä, vaikka siitä ei tullut vakinaista kuten suutarille, joka lonkaisen nimeä kantoi kuolemaansa asti.

Turjus sanontaa käytetään toisinaan henkilöistä, jotka ovat pukeutuneet huolimattomasti. Turjus-tyyppejä on täällä aniharvoja, minkä johdosta sanaakin käytetään vähän.

Lihavaa, veltto-olentoista mieshenkilöä sanotaan usein lösöseksi. Kivijärvellä asui ennen toiselta paikkakunnalta sinne muuttanut mies, jota yleisesti kutsuttiin tällä nimellä. Mies oli muuten siivo ja hyväntapainen, vaan lihava ja laiska hän oli.

Rahvattu sanontaa käytettiin Kivijärvellä ennen aikaan yleisesti, ja sillä tarkoitettiin raipparangaistuksen saanutta henkilöä. Nykyisin (1943) tuota sanaa käytetään jonkin verran edelliseen vivahta-

3 Kotiseutu 1943, s. 90. 
vassa yhteydessä, niin että julkisesti varkaaksi tunnettua henkilöä, vaikkei häntä olisikaan tuomittu, sanotaan joskus rahvatuksi.

Käsäl ällä tarkoitetaan pienikasvuista, kumaraharteista miestä. Sellainen oli Kinnulassa Kievarin Käsälä. Samanlaisia tyyppejä oli ennen ja on vielä nytkin (1943) useita. - Kinnulassa oli myös mies, jota sanottiin Nassar-Neksiksi. Nassar tarkoitti yleensä pienikokoista, terävää miestä.

Myös Pelkosenniemeltä voidaan esittää vastaavia esimerkkejä. Ominaisuutta kuvaava yleinen kölppi-sana siirtyi erään poromiehen liikanimeksi. Oli toisia sanoja, jotka pysyivät yleisinä liikaniminä. Niinpä kähy, käheä-ääninen, oli Pelkosenniemellä nüin tunnettu, että kaikki tiesivät, ketä kulloinkin tarkoitettiin, kun kähyä mainittiin. Niinikään siellä tarkoitettiin yskänpaininpuulla kaikkia miehïa, joiden ryhti oli aina "rykimäasennossa". - Kustaa Vilkuna esittää samantapaisia esimerkkejä Nivalasta.4

Sekä varsinaisia liikanimiä, joiden toisena osana oli tavallisesti ihmisen ristimänimi (vrt. Vilkuna s. 94), että pelkkiä luonnehtimisnimiä, joilla kuvailtiin ihmisen ulkomuotoa, käyttäytymistä tai luonteenominaisuuksia, käytettiin kovin yleisesti, paljon enemmän kuitenkin miehistä kuin naisista. Vilkuna huomauttaa aivan oikein, että, 'jtsellisiin kuuluvalla irtoväellä oli liikanimi todennäköisesti kaikilla". Sosiologisesti kiintoisaa on, että liika- ja luonnehtimisnimiä käytettiin enimmäkseen siitä kansanosasta, jolla oli alhainen sosiaalinen status. Mahdollisesti siihen vaikutti sama yhteiskunnallinen ilmiö, joka meidänkin oloissamme aiheuttaa ärtyneisyyttä ja sopeutumattomuutta alemmalla sosiaalisella tasolla. Mutta myös historiallinen kehitys on tässä otettava varteen. Keskiajalla ja vielä sen jälkeenkin käytettiin asiakirjojen todistuksen mukaan kunniallisista miehistä nimiä, joita myöhemmin alettiin pitää rivoina ja herjaavina ja jotka sen vuoksi katosivat ainakin julkisuudesta.' Viimeksi sen tapaiset liikanimet jäivät yhteiskunnan alempiin kerroksiin kuuluville henkilöille. Sosiaalipsykologisesti olisi kiintoisaa tarkoin ottaa selville, mihinkä aikaan ja millaisten olosuhteiden vallitessa mielet alkoivat tulla nuin herkiksi, että ihmiset katsoivat heitä luonnehtivien nimitysten muuttuneen haukkumanimiksi, joiden jul-

4 KustaA Vilkuna Thmisten puhuttelua edessä ja takana. Kotiseutu 1958, s. 96 . 
kinen lausuminen loukkasi heidän kunniaansa.5 Sitä ennen oli jo suurelta osalta lakattu käyttämästä liika- ja luonnehtimisnimiä talollisväestä, mihin Vilkunakin viittaa.

*

Tässä yhteydessä käsitellään sanotun kilpakeräyksen aineistoa vain siltä osalta, jossa kuvaillaan ihmisten fyysisiä piirteitä ja omituisuuksia. Tarkastelun näkökulma ei ole kielitieteellinen, vaan mahdollisuuksien mukaan sosiaaliantropologinen ja sosiologinen. ${ }^{6}$

1. Vartalon rakenneja muoto

Solakalla, hoikalla, laihalla ja pitkänpuoleisella miehellä on moninaisia nimityksiä: hutipuikkar, laiha ja pitkänsolakka (Lappi .T.1.), horkamoo, pitkä ja laiha, vähän luiseva sekä kruikelo ja laihan kälppi (Laihia). Hoikanpitkällä henkilöllä on Kivijärvellä monia määreitä: koikale, kuikero, kuikale, vonkale, votkula, votkale, rojo ja roikale. Pitkänhuiskea, komeahko nuori nainen, jonka koko olemus on sulavaa ja vapaata, on Kivijärvellä saanut yleisnimekseen heikale. Pitkä, laiha poika on Kaarinassa laikkari ja vastaavanlainen tyttö laitana. Luonnottoman pitkä ihminen, joka samalla on heikko ja laiha, on haippo (Pelkosenniemi).

Myös vertauksin kuvataan pitkää ja hoikkaa miestä. Pitk miäs, semmonko: taevan tönkkö (tukipuu, Lappi T.1.). Kukas toi pitkä raja tuola on? (Vampula). Hoikka kun heinä (Laihia), humalaseiväs (Mouhijärvi), hauvakaivaja kynsistä karannu, kalpea ja laiha, hautuumua aijaseiväs, laiha ja pitkä mies (Sortavala).

Lyhyellä ja samalla tanakalla ihmisellä on niinikään monia nimityksiä. Lyllerö, lyhyt ja lihava (Laihia), päljtsikk̈̈, lyhyt, tanakka ja leveäkasvoinen (Vuoksenranta), tyvikappale, tanakka (Marttila), lyllykkä, lyllerö, massukka, pumpero, tassukka ja tuppura, lyhytkasvuinen, lihavahko nuorehko nainen (Karstula). Pak-

5 Käräjänkäynnin huomattava kasvu viime vuosisadan loppukymmeninä saattaa viitata kunnianloukkausjuttujen lisääntymiseen. Esko AALTONEN Muutokssia maaseudún oloissa suuren murroksen ajoilta; s. 32. Turun hist. ark. XI.

6 Kursivoidut sanat ja lauseet esitetään lähettäjien kulloinkin kirjoittamassa muođossa. 
sut ja lyhyet ihmiset saivat liikanimekseen myös pöntiä (Vuoksenranta), tömyri (Lappi T.1.), jukopönkä (Laihia) ja myllytynnyri, lyhyt ja vahva tytär (Pelkosenniemi). Pienikokoista, laihaa ihmistä, joka ei vielä ole täysikasvuinen, määritellään nimillä ruupiainen, keäpiäinen ja keäpiö, pienikasvuista, kumaraharteista miestä taas nimellä $k a ̈ s a ̈ l a ̈$; pienikokoista terävää miestä sanotaan nassariksi ja pienikokoista naista napukaksi. Heikkorakenteinen ja vähäkuntoinen ihminen on reäpylä ja tämän rinnakkaisina merkityksinä ketkale; rähmä, reäme, räpyskä, reätti ja sirvelö (Kivijärvi).

Lyhyt, pieni tai vähäinen ihminen on saanut vielä seuraavia nimityksiä: irvana, samalla surkean näköinen, rääppöö, surkuteltavan näköinen (Laihia), paarakas, näälikäs, kärräkäs, nyrä, nörri, tumpukas (Lappi T.l.), kuikelj, laiha, kuiva ja ujo nuori mies, etupäässä poika (Sortavala), kuikka, pieniruokainen (Parikkala) ja kuikkana, huono syömään (Vuoksenranta).

Isokokoista ihmistä, joka samalla on riski, voimakas, määritellään mm. seuraavanlaisilla nimillä: siukas, isokokoinen, ryhdikäs (Lappi T.1.), ronkka, riski mies (Sysmä), vinkiä, suuri, komea ja roteva, riuska, suuri ja komea (Vuoksenranta), jolska, isohko ja sievä sekä jäykk ä; iso ja voimakas (Laihia), rohmakka, riski (Puolanka), komeli, suurikokoinen (Mouhijärvi).

Karstulan ja Kivijärven osuus isokokoisten ja lihavahkojen ihmisten kuvailussa on jälleen runsas. Tällaisia tavallisesti keskiikään kuuluvia miehiä kutsutaan nimillä juhmura, kössikkä, metju, vähkyrä, vähnikäs, vähnys ja ähväkänttyrä. Lähettäjä selittää: "Nämä tyypit ovat täällä aina olleet harvinaisempia, eikä niitä nykyisinkään monta löydy, sillä lihavat, hyvin syöneet miehet asustavat rikkaammilla rintamailla." - Isohkosta, lihavasta naishenkilöstä käytetään nimityksiä levennos, remma ja tuhtimamma. Isokokoiset ja lihavat, enimmäkseen vanhahkot miehet ovat saaneet nimekseen ruhnikka, runttea, rutjake ja vihny, samanlaiset naiset taas lähnikäs, muhnikka, murtikas, mömmerö ja ryhnikäs. Pamppu on tanakkatekoinen, lihavahko ja nuorehko naishenkilö, esim. piijampamppu. Hönkäle, hötkë̈ on taas isohko, reipasolentoinen nuorehko nainen, josta mm. sanotaan: "Siinä on aika hönkäle, jolla on näkköä ja kokkoa eissä ja takana ja kuppeella kummallaki." Karstulan tienoilla sanoo J. Leppänen sellaisen miestyypin olevan yleisen, joka on lihavahko, pyöreämuotoinen ja vilkaseleinen. Sen 
nimenä on kääkkylä, käätti ja nappula. Kun isokokoinen ihminen on samalla veltto, häneen liitetään sellaisia nimikkeitä kuin kutvellos, kähnys, köhnys, velepus ja vetkale.

Iso ihminen saattoi arvostelijainsa mielestä olla luisevuutensa takia ruma. Körmy, kormu, korsto on suuri, luiseva, ruma mies (Mouhijärvi), rontti, iso ja vähän luiseva (Laihia). Pelkosenniemellä käytetään sanaa kopes: 'kovin on kovan ja luisevan näköinen niin kuin ainakin kopes". Miellyttävä ei varmaan ole myöskään isovatsainen, kyhmyhartiainen ja hidasliikuntoinen neito, jota sanotaan kumuraksi (Pelkosenniemi).

\section{Käveleminen ja mu liikunto}

Kävelemistä kuvailtiin ensinnäkin antamalla ihmisille nimityksiä jalkojen eli raajojen mukaan. Kupilas on vanha, hidasliikkeinen mies:" on sellainen ukonkupilas (Sortavala). Kähmäleellä tarkoitetaan Mouhijärvellä kankeajalkaista, ja saman pitäjän sanastoon kuuluu myös muuallakin yleinen pillikinttu, pienisäärinen. J. Leppäsen kokoelmassa Karstulan Kivijärveltä on runsaasti ihmisen kävelyä ja raajoja kuvaavia sanoja. Konkkapolvinen kävelee jalat koukussa, linkkasäärisen jalat ovat kaareutuneet sisäänpäin, länkisäärisen ulospäin, ja linkkanivunen on heikkoraajainen, jonka jalat hetkahtavat sisälle päin samalla kuin koko vartalo notkuu. $N y$ tky on henkilö, joka kävelee hiukan etukumarassa ja nytkyttelee vartaloaan (käytetään lähinnä miehistä). Nytky nytkyy ja polovet hytkyy. Tämän rinnakkaismuotona on velttapolvi. Henkilö, joka kävelee etukumarassa ja huojuttelee yläruumistaan kuin sarvikelkan työntäjä, on saanut nimekseen työntäinen; 1940-luvun alussa eli Kivijärvellä mies, joka oli mainituista kävelyominaisuuksista saanut Työntäisen nimen.

Haakuraksi sanotaan Pelkosenniemellä pitkäsääristä naishenkilöä. Myös vertauksia käytettiin: jalat ku pyty kannet sanottiin henkilöstä, jolla oli lyhyet ja leveät jalkaterät (Sortavala).

3. Vatsa, hartiat ja selkä, niska ja kaula

Edellä on jo tullut esitetyksi luonnehtimissanoja, jotka muun ohêla kohdistuvat mvös vatsaan, hartioihin ja selkään. Mainitta- 
koon vielä joukko nimityksiä, joissa päähuomio on nimenomaan kiinnitetty näihin ruumiinosiin.

öhrys on paksumahainen ihminen, kumura isovatsainen, kyhmyhartiainen ja hidasliikuntoinen nainen (Pelkosenniemi) ja paaravassa isomahainen (Vuoksenranta). Kivijärvellä käytetään isovatsaisesta ihmisestä nimityksiä rapamaha, rumppumaha tai kellikkamaha. Sananlaskunomaisesti sanottiin: "Kyllä sitä kaikilla on rahhoa, mutta ei oo kellikkamahhoa". Leveähartiaisesta miehestä käytetään Kaarinassa vertailua: Sil on hartjakki nïn ku laron pääty. — Kumaraselkäinen on Mouhijärvellä köyssyselkä, Hämeessä yleensä kyssäselkä. Tisari on suuririntainen (Mouhijärvi).

Kyssyniska tai jämäniska on niskastaan paksu ja samalla kumara (Mouhijärvi); sankaniska kulkee kuin lautapä̈̈ härk̈̈ (Merikarvia). Kenokaula tai kekkapeä on Karstulan puolessa sellainen ihminen, jonka pää on kallellaan, kun taas pitkäkaulaista ihmistä kuvataan Laihialla sanakuvalla kaula kun kirvesvarsi, johna pääkulta kiikkuu.

\section{4. $P \ddot{a} \ddot{a}$}

Ihmisen pään rakennetta ja sen yksityiskohtia on erityisen tarkasti tutkittu ja pantu merkille "normaalista" erottuvat muodot. Kalttopää on ihminen, jonka otsa kallistuu huomattavasti päälakeen päin, jolloin takaraivo usein ulkonee luonnottomasti taakse päin. Kolonaamasella ovat "korvat niin kuin ohraleivän puolikkaat" (Kaarina). Ihmistä, jolla on sisään painuneet posket, sanotaan Karstulassa pulloposkeksi tai loppaposkeksi. Koska meillä suomalaisilla on nenänmalleja monenlaisia, löytyy myös vastaavia nimityksiä runsaasti. Lestikuonoksi sanotaan henkilöä, jolla on suuri, sisään päin kovero nenä (Kaarina). Ulospäin kaareva nenä on konkonenä, könönenä, kiverä ja teräväpäinen nenä on pysty- tai piipulanokka, kun taas karvanokaksi sanotaan miestä, jonka sieraimista pistää vlos karvatöyhtö.

Ihmisen suusta ja varsinkin huulista on huomattu erilaisuuksia. Lipsasuun alahuuli on ylähuulta pitempi (Vuoksenranta) ja harahuulen huulet ovat avoinna (Kaarina). Lerppahuulesta puhutaan Merikarvialla ja yleisesti muuallakin. Thminen, jolla on paksut ulkonevat huulet, on Karstulassa römöhuuli ja hänestä sanotaan: "Sen huulista tulisi vaikka viisi paria rahkeita". 
Korvista on nyt käsiteltävänä olevassa kokoelmassa suhteellisen vähän määritelmiä. Leppakorva tai reppakorva on henkilö, jolla on suuret, ulkonevat korvat (Kivijärvi). Kuten kolonaamaa verrataan Kaarinassa leveitä korviakin ohraleivän puolikkaisiin. Varsin moninaisesti on luonnehdittu ihmisen silmiä. Kïrotin on pikkusilmäinen ihminen, joka rypistä̈̈ silmiä kokho (Pelkosenniemi). Herasilmä on ihminen, jonka silmä juoksee vettä ja punoittaa, ja mulkkisilmällä on ulkonevat silmät (Kaarina). Siansilmistä puhuttiin yleisesti, kun tarkoitettiin ihmistä, jolla oli pienet silmät. Kaarinasta tunnetaan hokema: Pienes silmä, suurek korva, sia lai, sia lai. Pienek korva, suures silmä, herrastai, herrastai.

J. Leppäsen kokoelmassa Karstulan Kivijärveltä on runsaasti ihmissilmien erilaisuutta kuvaavia sanoja. Näistä mainitaan tässä vain muutamia kuvaavimpia. Kun ihmisellä on vaaleat, sinertävänsameat silmät, hän on herasilimä. Ihminen, jolla on hyvin liikkuvat ja "ulkonevat silmämunat, niin että usein vain "paljaat valkuaiset koljottavat näkyvissä", on mulukosilimä. Mulukoiloo kum posetiivar ja soipa mehto. Parrisilimällä on avarat, pyöreän rengasmaiset ja terävästi katselevat silmät. Tuo parrisilimä kahteloo ku hïriäishaukka, ihan toise ihmisel läp. Kun naisella on avarat, pyöreähköt ja hyvin eloisat silmät ja kun hänellä muutenkin on hyvä ulkomuoto ja eloisa luonne, saa hän kehumanimen lirusilimä.

Myös parta, kasvojen muu karvaisuus ja hiustenkasvu on joutunut tarkkailtavaksi. Tussari on parrakas ukko (Pelkosenniemi), sutiparta on mies, jolla on viikset (Kivijärvi) ja karvaposkesta sanotaan Kaarinassa: "Siitä on susi meinattu, mutta karvat loppuneet kesken". Punatukkainen mies on tulipää (Kaarina) ja kahupiällä kasvaa runsas tukka, mutta se on hoitamaton (Sortavala).

Thmisen ihosta ja sen väristä on niinikään runsaasti määritelmiä. Rokonarpisia ihmisiä oli entisaikaan paljon isonrokon jäljiltä. Heistä sanottiin: "Se on ollut pirun kans papuriihellä" (Lappi T.1.). Vihantapintainen on kaunisihoinen ihminen (Vuoksenranta), haalinkhainen on kalpeavärinen, siukka ja nattakauha on laiha ja valkia (Pelkosenniemi) sekä kaiskerainen heiveröinen ja kalpea (Vuoksenranta). Harmaantuneesta vanhuksesta sanottiin Sortavalan puolessa, että hän oli harmaa ku hyyppii (huuhkaja).

Hampaihin kohđistuneita luonnehtimisia on kokoelmassa vähänpuoleisesti. Mainittakoon vain Kivijärveltä muutamia. Roukko- 
hammas tarkoittaa sitä, että hampaat ovat kasvaneet edestakaisin sisään ja ulos päin, joten hammasrivi on epätasainen. Harvahammas on yleinen; sillä kuvattiin entisaikaan myös luonnetta, ihmistä, jonka puheisiin ei ollut uskomista. ${ }^{7}$

Thmisten luonnehtimisnimiin kuuluvat myös eri ikäkausia osoittavat "lajinimet". Kokoelmassa on näistä esimerkkejä vain nuorista pojista: nulja, nulkki, kyärti, 10 ikävuoden kahden puolen, nuija, pahankurinen poika, pirun kokonen, alle 10-vuotias poika, nöosi, yleensä pikkupoika, kölvi ja nölvi, keskenkasvuinen poika (kaikki Mouhijärveltä).

Ihmisen ulkomuodon arvostaminen ja esteettisen ihanteen tavoittaminen ei entisaikaan liene ollut varsin tärkeätä. Sananparren mukaan "ei muoto murkinaksi kelpaa" (Viljakkala). Mutta kuten eräistä edellä esitetyistä esimerkeistäkin huomataan, ilmaistiin käytetyillä luonnehtimissanoilla kyllä, mitä muotoa suosittiin, mitä ei. Eräät vastaajat ovat asian tästä puolesta tehneet merkintöjä, mutta nämä ovat sittenkin jääneet satunnaisiksi, ja jossakin täydennyskeräyksessä tähän sosiaalipsykologisesti kiintoisaan seikkaan on kiinnitettävä erityistä huomiota.

Nykyisestäkin aineistosta voidaan kuitenkin poimia esimerkkejä siitä, millaista ihmistä pidettiin miellyttävänä, minkä näköistä epämiellyttävänä. Nätsikës esim. on sieväkasvoinen nainen (Mouhijärvi), ja Kivijärvellä käytetään miellyttävän näköisistä ja miellyttävän tuntoisista ihmisistä, jotka enimmäkseen ovat tyttöjä, sellaisia luonnehtimisnimiä kuin siepperä ja sieppeä, nimenomaan kuvatunlaisesta nuoresta naisesta myös sätterä. Kauniina ja komeana pidetään Pelkosenniemellä henkilöä, joka on sinisilmäinen, punaposkinen, valkeaverinen, keltahiuksinen ja sievä raatonen sekä kooltaan tavallinen; mustasilmäistä ei pidetty ihmisenäkään. ${ }^{8}$

Epämiellyttävänä pidetään henkilöä, jolla on huono vartalo ja jolsat kasvonpiirteet. Sellainen ihminen sai liikanimekseen haituni:

7 Kalle Nieminen Jämsästä mainitsee sanalipuissaan sellaisia muotoja kuin kalsohammas, töröhuuli, hottisuu, herosilmä, hättäräsilmä, lihtajaltca ja repsaposki, mutta hän ei selitä niiden merkitystä. Thmisen suusta hänellä on seuraava kuvailu: "Suu on kun Viron veräjä".

8 Vrt. Esko Aaltonen Kansannainen 70 vuotta sitten. Pellervo 1958/10. 
ei se kelepoa kellenkään, kun se on niin kovij jolsa-haituni. Kankea mies, jolla on tylsän ilmeiset kasvonpiirteet, karkea puhetapa ja huono käytös, saa määreekseen kölöpiö, ööpi; kolopero, tolovasti, pörkkäa, jopelo, köriläs. J. Leppänen mainitsee, että tällaisia tyyppejä ei Karstulan tienoilla ollut paljon. -- Rumaa ja epämiellyttävää ihmistä sanotaan Mouhijärvelläkin jolsaksi, rumaa naista Pelkosenniemellä törsilöksi.

Vialloisella ihmisellä oli sattuvia nimityksiä. Jos jollakulla esim. oli toinen puoli ruumista vähän toista puolta pitempi ja heikompi, annettiin hänelle määre haminapuol; lonkkapuolinen oli vielä yleisemmin käytetty määre sellaisesta henkilöstä (Kaarina).

Toivon voivani esitellä jossakin toisessa yhteydessä ihmisten luonteenominaisuuksiin kohdistuvia nimityksiä ja vertauksia, joiden runsaus ja osuvuus on niinikään silmäänpistävä.

Esko Aalronen: Über die volkstümliche Art, das Aussehen der Menschen zu charakterisieren

Der Aufsatz behandelt die reichhaltige, aus Ergebnissen einer folkloristischen Umfragung bestehende Sammlung finnischer Wörter und Redensarten, womit im Volk das Aussehen und die Charaktereigenschaften der Mitmensehen bezeichnet und gegebenenfalls auch bekrittelt wurden. Aus dem Material geht hèrvor, dass vormals auf dem Lande in den unteren Bevölkerungsschichten zunäehst den Männern in Betracht ihres Benehmens, ihres Äusseren oder ihrer Charaktereigenschaften zweierlei Spitznamen angehängt wurden. Der eigentliche Spitzname enthielt gewöhnlich den Taufnamen des Betreffenden; die auf irgendwelche spezielle Eigenschaften hinweisenden Namen waren frei erfundene Appellativa und so deskriptiv wie nui irgend möglich. Ausserdem gebrauchte man Vergleiche und Wortverbindungen.

Der vorliegende Aufsatz befasst sich nur mit einer Auswahl von Wörtern und Redensarten, die sich auf das Äussere beziehen: auf den Körperbau, die Körperteile (vor allem den Kopf) und auf den Gang. Sie werden jedoch nicht aus dem Sehwinkel der Sprachforschung, sondern zunächst von soziologischem und änthropologischem Standpunkt aus betrachtet. Verf. Ienkt die Aufmerksamkeit u.a. auf die Erscheinung, dass realistische Spitznamen und charaktervigeńschaftliche Benennungen früher nicht gescheut wurden; in den letzten Jahrzehnten des vergangenen Jahrhunderts, als auch die unteren Bevölkerungsschichten sich zu regen begannen, von einem Ort zum anderen ziehend, wurden jedoch derartige Namen bald als Beschimpfungen aufgefasst und allmählich. im Laufe der Zeit, versehwanden sie grösstenteils aus dem Gebrauch. 